University of Nebraska - Lincoln

DigitalCommons@University of Nebraska - Lincoln

2006

RAPID ONSET OF TRANSMISSION-REDUCING ANTIBODIES IN JAVANESE MIGRANTS EXPOSED TO MALARIA IN PAPUA, INDONESIA

\author{
J. Teun Bousema \\ Department of Medical Mirobiology 188, Radboud University Nijmegen Medical Centre \\ Will Roeffen \\ Department of Medical Mirobiology 188, Radboud University Nijmegen Medical Centre \\ Mike van der Kolk \\ Department of Medical Mirobiology 188, Radboud University Nijmegen Medical Centre \\ Sake J. de Vlas \\ Department of Public Health, Erasmus University Rotterdam \\ Marga van de Vegte-Bolmer \\ Department of Medical Mirobiology 188, Radboud University Nijmegen Medical Centre
}

See next page for additional authors

Follow this and additional works at: https://digitalcommons.unl.edu/publichealthresources

Bousema, J. Teun; Roeffen, Will; van der Kolk, Mike; de Vlas, Sake J.; van de Vegte-Bolmer, Marga; Bangs, Michael J.; Teelen, Karina; Kurniawan, Liliana; Maguire, Jason D.; Baird, J. Kevin; and Sauerwein, Robert W., "RAPID ONSET OF TRANSMISSION-REDUCING ANTIBODIES IN JAVANESE MIGRANTS EXPOSED TO MALARIA IN PAPUA, INDONESIA" (2006). Public Health Resources. 391.

https://digitalcommons.unl.edu/publichealthresources/391

This Article is brought to you for free and open access by the Public Health Resources at DigitalCommons@University of Nebraska - Lincoln. It has been accepted for inclusion in Public Health Resources by an authorized administrator of DigitalCommons@University of Nebraska - Lincoln. 


\section{Authors}

J. Teun Bousema, Will Roeffen, Mike van der Kolk, Sake J. de Vlas, Marga van de Vegte-Bolmer, Michael J. Bangs, Karina Teelen, Liliana Kurniawan, Jason D. Maguire, J. Kevin Baird, and Robert W. Sauerwein 


\title{
RAPID ONSET OF TRANSMISSION-REDUCING ANTIBODIES IN JAVANESE MIGRANTS EXPOSED TO MALARIA IN PAPUA, INDONESIA
}

\author{
J. TEUN BOUSEMA, ${ }^{\dagger}$ WILL ROEFFEN, $†$ MIKE VAN DER KOLK, $†$ SAKE J. DE VLAS, \\ MARGA VAN DE VEGTE-BOLMER, MICHAEL J. BANGS, KARINA TEELEN, LILIANA KURNIAWAN, \\ JASON D. MAGUIRE, J. KEVIN BAIRD, AND ROBERT W. SAUERWEIN \\ Department of Medical Microbiology, Radboud University, Nijmegen Medical Centre, Nijmegen, The Netherlands; Department of \\ Public Health, Erasmus Medical Centre, University Medical Center Rotterdam, The Netherlands; U.S. Naval Medical Research Unit \\ No. 2, Jakarta, Indonesia; National Institute of Health Research and Development, Jakarta, Indonesia
}

\begin{abstract}
Transmission of Plasmodium falciparum malaria is initiated by sexual stages in the mosquito. Anti-Pfs48/ 45 and anti-Pfs 230 sexual stage antibodies that are ingested together with parasites can reduce parasite development and subsequently malaria transmission. Acquisition of sexual stage immunity was studied in a cohort of 102 non-immune Javanese individuals migrating to hyperendemic Papua Indonesia. Seroprevalence of antibodies against Pfs $48 / 45$ and Pfs230 and functional transmission-reducing activity (TRA) were measured upon arrival and at 6, 12, and 24 months. Asexual parasitemia and gametocytemia were assessed every two weeks. The TRA and seroreactivity increased with the number of $P$. falciparum infections. The longitudinally sustained association between TRA and antibodies against Pfs $48 / 45$ (odds ratio $[\mathrm{OR}]=3.74,95 \%$ confidence interval $[\mathrm{CI}]=1.51-9.29)$ and $\mathrm{Pfs} 230(\mathrm{OR}=3.72,95 \% \mathrm{CI}=$ 1.36-10.17) suggests that functional transmission reducing immunity is acquired after limited exposure to infection.
\end{abstract}

\section{INTRODUCTION}

Successful transmission of Plasmodium falciparum parasites from humans to mosquitoes depends on the presence of infectious gametocytes in the circulation, which are derived from a small fraction of asexual parasites. After ingestion of the blood meal by mosquitoes, fertilization takes place in the midgut, which will ultimately result in the generation of infectious sporozoites in the salivary glands. Specific antibodies against sexual stages can interfere with fertilization and subsequent sporogonic development when co-ingested with the blood meal, as shown in natural and experimental infections. ${ }^{1-4}$ This transmission-reducing activity (TRA) is associated with antibodies directed against the sexual stage-specific antigens Pfs $48 / 45$ and Pfs $230{ }^{5-8}$ The rate of development and persistence of TRA is largely unknown. Although it was suggested to be low grade and rapidly transient, ${ }^{9}$ persistent TRA has also been observed. ${ }^{10}$ Acquisition of immunity directed against asexual blood stage parasites has been intensively studied people migrating from a non-endemic to a malariaendemic area. ${ }^{11-15}$ In these transmigrants, clinical and parasitologic immunity developed quickly after exposure ${ }^{13}$ with inconsistent evidence for an independent role of age. ${ }^{11-16}$

The objective of this study was to examine the development of sexual stage-specific immunity in a longitudinal cohort of Javanese children and adults from non-endemic Java after migration to malaria endemic Papua. Antibody reactivity against sexual stage-specific antigens Pfs 230 and Pfs $48 / 45$ was determined and compared with antibodies against asexual stage antigen glutamate-rich protein (GLURP) and whole parasite extracts. The GLURP-specific antibodies have previously been associated with protection against high levels of parasitemia ${ }^{17}$ and clinical disease. ${ }^{18-20}$ The development of sexual stage-specific immunity was evaluated by detecting circulating antibodies against Pfs 230 and Pfs $48 / 45$ and by assessing functional TRA in the standard membrane-feeding assay.

* Address correspondence to J. Teun Bousema, Department of Medical Microbiology 268, Radboud University Nijmegen Medical Centre, P.O. Box 9101, 6500 HB Nijmegen, The Netherlands. E-mail: t.bousema@ncmls.ru.nl

$\dagger$ These authors contributed equally to this work.

\section{MATERIALS AND METHODS}

Study population. The study site was a newly created transmigration village (designated SP2) located near the northeastern coast of Papua, Indonesia. After informed consent was obtained, healthy volunteer adults between 20 and 40 years of age and children between 6 and 12 years of age were included in the study. The study was reviewed and approved by the institutional ethical review boards of the United States Navy and the Indonesian Ministry of Health under U.S. Department of Defense Protocol \#30820. The included human subjects were treated according to relevant regulations of the Indonesian Ministry of Health and the United States government (code 32 of Federal Regulation, Part 219, Protection of Human Subjects; U.S. Navy, SECNAVINST 3900.39B). Subjects were excluded if admitting a history of residence in a malaria-endemic area in the previous five years. Details on recruitment, follow-up, and the epidemiology of malaria in this cohort have been described elsewhere. ${ }^{16}$ Enrollment started in 1996 and follow-up ended in 1999. The subjects originated from Java and were enrolled in the study within 48 hours of arrival in Papua, Indonesia. Malaria transmission in Java has been very low for many decades, typically around 0.01 malaria cases/1,000 person-years after the exclusion of the few foci of hypoendemic transmission. ${ }^{21}$ In contrast, malaria transmission in Papua is perennial and often hyperendemic to holoendemic, with incidence rates from 500 to 5,000 infections/1,000 person-years. ${ }^{22}$

Follow-up. Malaria episodes were actively detected over a period of 24 months by periodic clinical assessments and blood smears. Blood smears were collected at two-week intervals or at any time a subject presented to the clinic with symptoms (chills, fever, etc.) suggesting malaria infection. Blood was microscopically examined for $P$. falciparum and $P$. vivax asexual parasites and gametocytes by Giemsa-stained blood films. Parasites were counted against the number of white blood cells. A slide was considered negative after examination of 200 microscopic fields, corresponding to 1,6002,400 white blood cells and an estimated diagnostic threshold of five parasites per microliter. Parasite densities were calculated using a normal density of 8,000 white blood cells per 
microliter of blood. The first episode of symptomatic or asymptomatic $P$. falciparum malaria was recorded as first infection. Each subsequent $P$. falciparum parasitemia was classified as a new infection if it occurred more than 28 days after directly observed chemotherapy of the previous infection. Sera were collected on the day of arrival and after 6,12 , and 24 months at SP2. ${ }^{12,14,16}$ To study the acquisition of immunity in time, we selected samples from subjects for whom at least three samples were available. We selected 51 subjects 6-12 years of age and 51 subjects $20-40$ years of age. The incidence of malaria infection in these individuals was not different from that of the general population.

Enzyme-linked imunosorbent assays (ELISAs). Antigen preparation. Mature gametocytes of P. falciparum (NF54 strain) were produced in an automated static culture system as described by Ponnudurai and others, ${ }^{23}$ isolated, ${ }^{4}$ and stored at $-70^{\circ} \mathrm{C}$ until used. The NF54 gametocytes were extracted in $25 \mathrm{mM}$ Tris- $\mathrm{HCl}, \mathrm{pH} 8.0$, supplemented with 150 $\mathrm{mM} \mathrm{NaCl}, 1.0 \%$ sodium desoxycholate, and $1 \mathrm{mM}$ phenylmethylsulfonyl fluoride. Samples were centrifuged at 13,000 $\times$ $g$ for 5 minutes at room temperature to remove insoluble debris and the supernatant was used as source of wholeparasite antigen (Pfs48/45 and Pfs230).

$P f_{s} 230$ and $P f_{S} 48 / 45$ capture ELISA. IgG antibodies to Pfs230 were assayed by coating Sterilin ${ }^{\circledR}$ ELISA plates (no. 53011; International Medical Products B.V., Zutphen, The Netherlands) with mouse monoclonal antibody (MAb) 63F6D7-F(ab $)_{2}$ fragments $(10 \mu \mathrm{g} / \mathrm{mL})$ in phosphate-buffered saline (PBS), $\mathrm{pH}$ 7.4. For Pfs48/45, the plates were coated with rat MAb 85RF45.3. Plates were blocked with 5\% (w/v) low-fat dry milk (Marvel, Premier International Foods Ltd., Spalding, United Kingdom) in PBS. For Pfs 230 or Pfs $48 / 45$ antigen capture, plates were incubated with gametocyte extract (250,000 parasite equivalents/well). Serum samples (1: 100 dilution) were added to the wells and incubated for two hours. Bound $\mathrm{IgG}$ antibodies were detected by horseradish peroxidase-labeled goat anti-human IgG (31412; Pierce Biotechnology, Inc., Rockford, IL). The wells were washed three times with PBS and incubated with tetramethylbenzidine substrate solution for 20 minutes. The color reaction was stopped with $4 \mathrm{~N} \mathrm{H}_{2} \mathrm{SO}_{4}$, and optical density (OD) was read at $450 \mathrm{~nm}$ (Anthos 2001 microplate reader; Labtec BV, Heerhugowaard, The Netherlands). All incubations were carried out at room temperature. All serum samples were tested in duplicate with a concurrent positive control and a minimum of four negative (Dutch blood bank donor) controls per plate. Sera were considered positive if the OD was $3 \mathrm{SD}$ above the mean of negative controls.

Whole parasite and GLURP ELISA. Antibodies against whole parasite extract and GLURP served as markers for general anti-parasite and specific asexual stage immunity, respectively. Sterilin ${ }^{\circledR}$ ELISA plates (International Medical Products B.V.) were coated overnight with 250,000 parasites per well with a diluted stock that contained $30 \times 10^{6}$ parasites/ $\mathrm{mL}$ in extraction buffer plus PBS. After blocking with $5 \%$ milk/PBS, serum samples were incubated for two hours at room temperature (1:100 dilutions in $0.1 \%$ milk, Tween 20 , PBS). Anti-GLURP ${ }_{85-213}$ antibodies were measured in plasma samples by ELISA. ${ }^{24}$ Microtiter plates (Nunc Maxisorp; Nalge Nunc International Corp., Roskilde, Denmark) were coated overnight at $4^{\circ} \mathrm{C}$ with $50 \mu \mathrm{L}$ of $0.2 \mu \mathrm{g}$ of GLURP $_{85-213} / \mathrm{mL}$ (final concentration) in $0.05 \mathrm{M}$ carbonate buffer, pH 9.6. The wells were washed Tween 20, PBS, and incubated with $2.5 \%(\mathrm{w} / \mathrm{v})$ milk in PBS. Plasma samples were diluted in $0.05 \%$ PBS, Tween $20,1.25 \%$ milk. For the detection of $\mathrm{IgG}$ antibodies to GLURP $_{85-213}$, rabbit anti-human IgG peroxidase (P-214; Dako, Glostrup, Denmark) was used at a dilution of 1:10,000 in $0.05 \%$ PBS, Tween $20,1.25 \%$ milk. These ELISAs were carried out as for Pfs 230 and Pfs48/45.

Standard membrane feeding assay (SMFA). Experimental infections of mosquitoes were carried out as previously described. ${ }^{25,26}$ Three-to-five-day-old colony-reared Anopheles stephensi were allowed to membrane feed on freshly cultured mature NF-54 P. falciparum gametocytes in batches of 50 mosquitoes each in the presence of serum. A maximum of 17 transmigrant serum samples were compared with three batches of a single (Dutch bloodbank donor) control serum. Immediately after the feed, non-fed and partially fed mosquitoes were removed. Blood-fed mosquitoes were kept at a temperature of $26^{\circ} \mathrm{C}$ and a relative humidity of $80 \%$ for seven days. Surviving mosquitoes (>90\%) were dissected and oocysts were counted in extracted midguts. Twenty mosquitoes per batch were examined for oocysts. An SMFA experiment was considered valid when the percentage of infected mosquitoes was $\geq 90 \%$ in all three control batches. The observed TRA of serum was determined as the percentage reduction in oocyst numbers in test samples compared with controls. ${ }^{27}$ Functional TRA was defined as a minimum of $50 \%$ reduction in oocysts numbers in the standard SMFA. Not all sera were analyzed in the SMFA because of resource limitations. A random sample of individuals was therefore selected and all available serum samples were tested in the same SMFA experiment.

Statistical analyses. Analyses focused on the relation between the development of (functional) sexual stage-specific immunity and cumulative exposure to $P$. falciparum, which was quantified as the cumulative number of infections with asexual stage $P$. falciparum parasites. Statistical analyses were carried out using SPSS for Windows version 10 (SPSS Inc., Chicago, IL) and Stata version 7.0 (Stata Corporation, College Station, TX). Prevalence of antibodies and functional TRA (dichotomous variables) as a function of exposure to asexual $P$. falciparum parasites were tested using multiple logistic regression models with generalized estimating equations (GEEs). Regression $\beta$ coefficients were calculated with 95\% confidence intervals (CIs). Prevalence was logit-linked analyzed. The number of infections was included as a continuous variable and a random effect was included in the models to allow for correlations within individuals. Age group (20-40 years versus 6-12 years) and number of $P$. vivax infections were included in the models as covariates. Interaction terms were added to the models to assess a possible modifying effect of age on the relation between exposure to infections and the development of immunity.

\section{RESULTS}

The malariometric indices of the study population are shown in Table 1. Most individuals experienced at least one episode of malaria, with a median number of three infections during the 24-month period of follow-up. Although prevalence of infection was similar for adults and children, the latter were exposed to higher densities of asexual parasites $(P=0.02$; Table 1$)$. Gametocytes were detected in $26 \%$ of 
TABLE 1

Characteristics and Plasmodium falciparum malariometric indices of 102 study subjects from the SP2 cohort during 24 months of follow-up in Papua, Indonesia*

\begin{tabular}{|c|c|c|c|}
\hline & Children & Adults & $P$ \\
\hline No. & 51 & 51 & \\
\hline Age, median (IQR) & $9(8-11)$ & $32(28-37)$ & \\
\hline No. $(\%)$ of individuals infected & $49(96.0)$ & $49(96.0)$ & 1.0 \\
\hline No. of infections per person, median (IQR) & $3(1-3)$ & $3(2-4)$ & 0.53 \\
\hline Asexual parasite density, GM (IQR) & $2,792(879-11,962)$ & $1,697(520-5,920)$ & 0.02 \\
\hline No. (\%) of individuals gametocytemic & $13(25.5)$ & $15(29.4)$ & 0.66 \\
\hline Gametocyte density, GM (IQR) & $112(40-280)$ & $176(48-579)$ & 0.21 \\
\hline
\end{tabular}

* $\mathrm{IQR}=$ interquartile range; $\mathrm{GM}=$ geometric mean parasite density in parasites $/ \mu \mathrm{L}$ for $P$. falciparum asexual parasite or gametocyte carriers only

the children and $29 \%$ of the adults with no statistically significant difference in gametocyte density.

The cumulative number of infections per six months is shown in Figure 1. By six months, $20 \%$ of the 102 migrants had experienced $\geq 2$ infections; by 24 months, this proportion had increased to $73 \%$. The cumulative number of subjects in whom gametocytes were observed in peripheral blood films was $0,2,8$, and 18 for time points $0,6,12$, and 24 months post-migration, respectively.

Seroreactivity against whole $P$. falciparum extracts and asexual stage-specific antigens increased with cumulative exposure (Figure 2A). Antibody prevalence in the whole parasite ELISA increased to $98 \%$ after two infections and was maintained after further infections. The prevalences of antibodies against sexual stage-specific antigens Pfs48/45 and Pfs230 were also increased after two infections (Figure 2B). The proportion of serum samples with TRA gradually increased from $10 \%$ (3 of 29) prior to migration to $27 \%$ (3 of 11) after more than four infections. There was a clear association between the presence of gametocytes at the time of sampling and TRA (odds ratio $[\mathrm{OR}]=5.22,95 \% \mathrm{CI}=1.87-$ 14.56). Nevertheless, only $31.3 \%$ (10 of 32) of sera with TRA were derived from individuals with patent gametocytemia at the time of sampling $(\mathrm{n}=9)$ or prior to sampling $(\mathrm{n}=1)$.
After adjustment for the number of infections, TRA was significantly associated with the prevalence of antibodies to Pfs48/45 (OR $=3.74,95 \% \mathrm{CI}=1.51-9.29)$ and antibodies to Pfs230 (OR $+3.72,95 \%$ CI $=1.36-10.17)$. No statistically significant association was observed between TRA and the prevalence of antibodies to whole parasites (OR $=4.21,95 \%$ $\mathrm{CI}=0.53-33.18)$ or antibodies to GLURP $(\mathrm{OR}=1.90,95 \%$ $\mathrm{CI}=0.83-4.34)$.

To adjust for a correlation between observations from the same individual and for potential confounders, a GEE model was used for statistical analyses of the data shown in Figure 2. There was a statistically significant increase in positive response after $P$. falciparum infections in all ELISAs, which was strongest for the whole parasite assay. There also was a statistically significant positive association between the prevalence of TRA and the number of infections (Table 2).

Seroprevalence of antibodies against Pfs230 (Figure 3), whole parasite, and GLURP were consistently higher in adults. In adults, $23.8 \%$ (10 of 42 ) of individuals had antibodies to Pfs 230 prior to exposure compared with $0 \%$ (0 of 32) of the children. This higher seroprevalence for adults remained apparent throughout follow-up. Although the intercept of the trend lines was higher in adults $(P=0.001)$, the slope of both lines was not different $(P=0.62)$, which indicated a similar

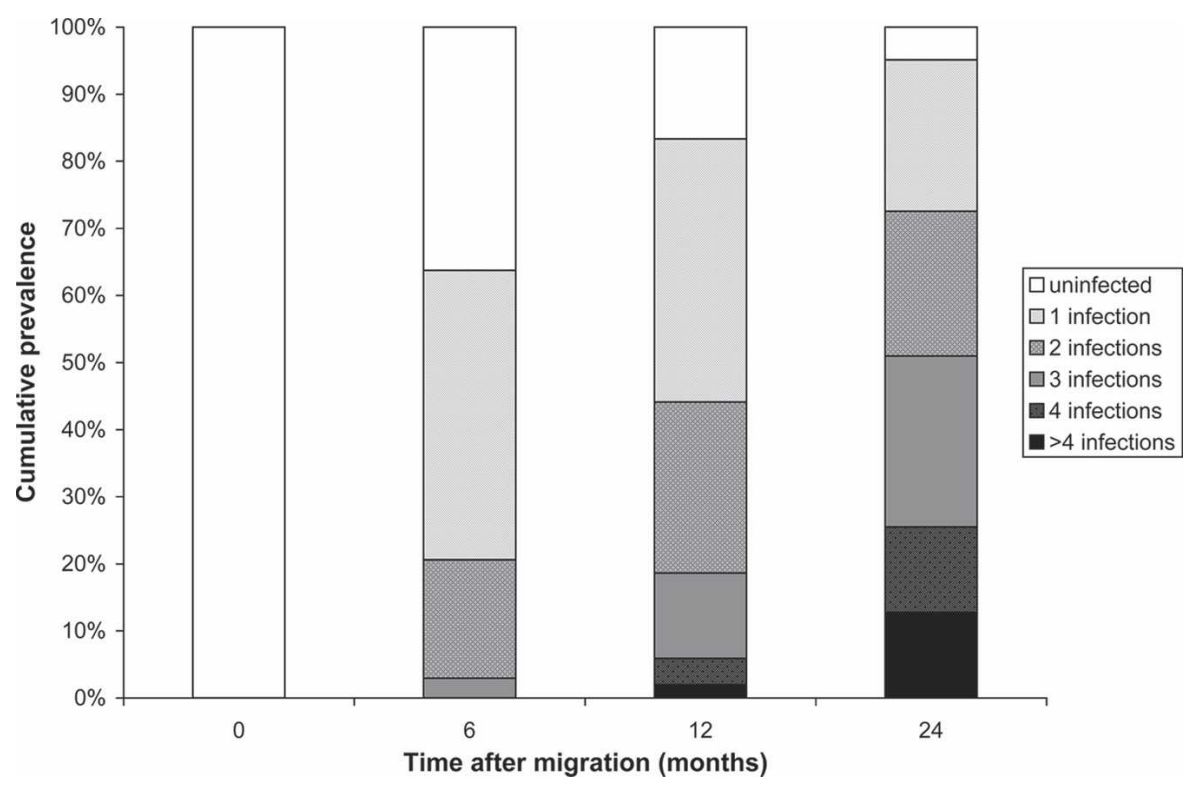

FIGURE 1. Cumulative prevalence of asexual stage infections in a cohort of 102 non-immune migrants from Java to Papua, Indonesia experiencing 1-4 four infections with Plasmodium falciparum during two years of follow-up in the malaria-endemic area. 


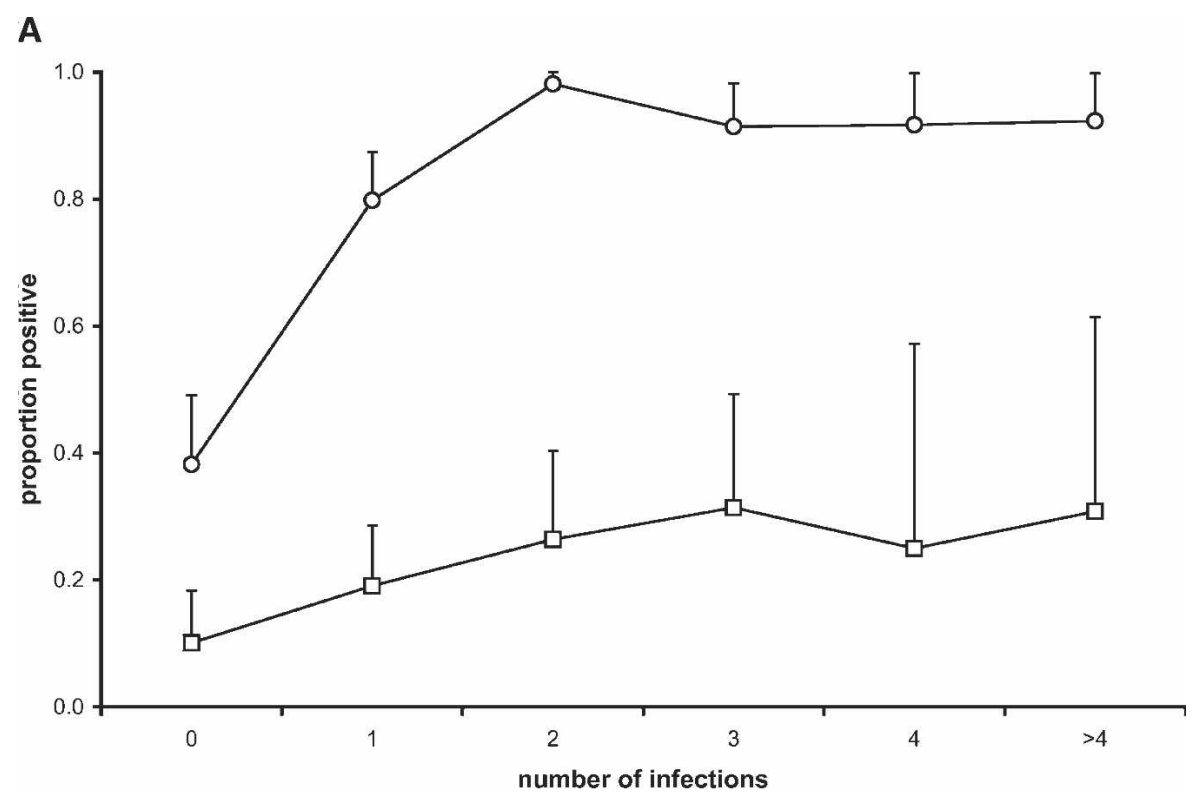

B

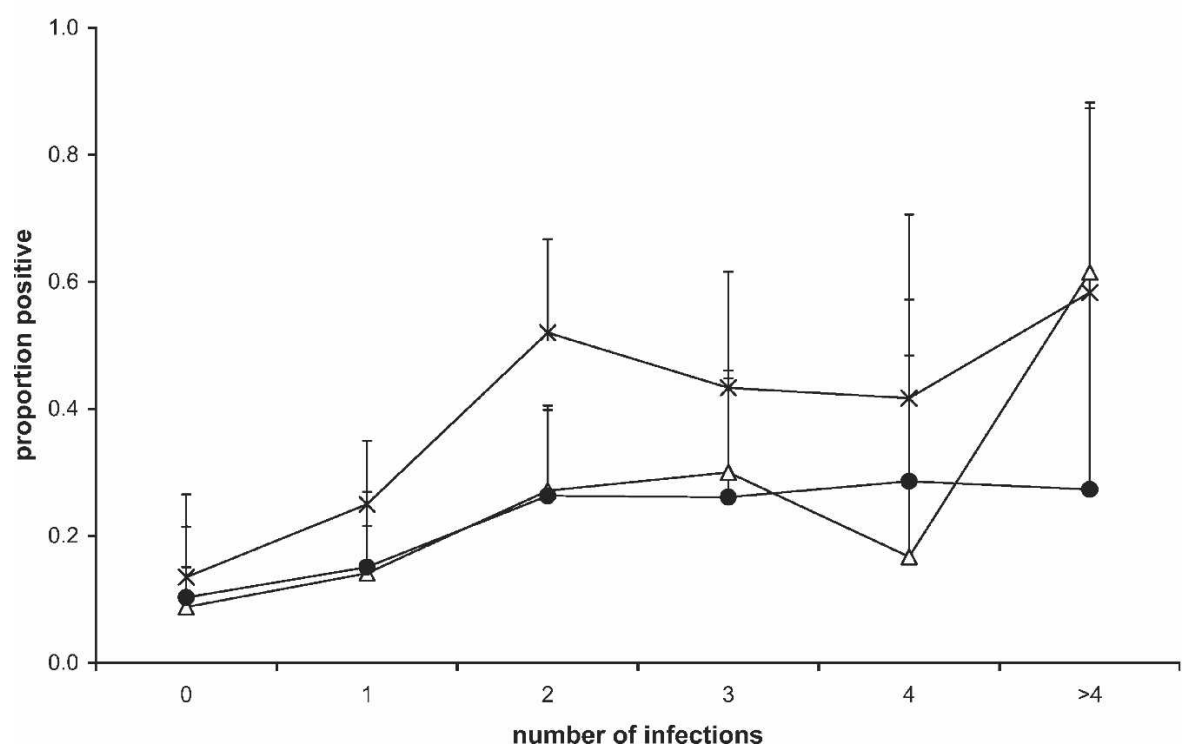

FIGURE 2. Proportion of serum samples with Plasmodium falciparum-specific antibodies as a function of the number of prior $P$. falciparum infections. A, Seroreactivity for whole parasite $(\bigcirc)$ and asexual stage-specific glutmate-rich protein $(\square)$. B, Seroreactivity for sexual-stage specific $\operatorname{Pfs} 230(\times)$ and Pfs48/45 $(\triangle)$, and functional transmission-reducing activity $($ TRA $)>50 \%(\bullet)$. For TRA, 20 mosquitoes were dissected per serum sample included in the standard membrane feeding assay. The control samples resulted in a median number of 21 oocysts (interquartile range $=$ 7-46) per mosquito. Error bars indicate the upper limit of the $95 \%$ confidence interval.

TABLE 2

Regression coefficient of the number of prior Plasmodium falciparum infections as a predictor of seroreactivity or transmission reducing activity*

\begin{tabular}{lrcr}
\hline & \multicolumn{1}{c}{ No. $\dagger$} & Positive response $(95 \% \mathrm{CI}) \ddagger$ & \multicolumn{1}{c}{$P$} \\
\hline Whole parasite & $102(296)$ & $1.30(0.64-1.96) \S$ & $<0.001$ \\
GLURP & $102(296)$ & $0.49(0.21-0.77) \S \mathbb{1}$ & 0.001 \\
Pfs48/45 & $95(268)$ & $0.40(0.24-0.57)$ & $<0.001$ \\
Pfs230 & $89(252)$ & $0.46(0.25-0.67) \S$ & $<0.001$ \\
TRA & $76(161)$ & $0.39(0.07-0.71) \Phi$ & 0.016 \\
\hline
\end{tabular}

* GLURP $=$ glutamate-rich protein; TRA $=$ transmission-reducing activity.

$\dagger$ No. of individuals (no. of measurements)

\$ Regression coefficient $\beta$ (95\% confidence interval [CI]).

$\$$ Estimate adjusted for age group.

II Estimate adjusted for number of $P$. vivax infections. relationship between number of infections and Pfs 230 seroreactivity for adults and children. In the GEE models (Table 2), the relationship between number of infections and whole parasite, GLURP, and Pfs230 seroreactivity was not different between children and adults.

\section{DISCUSSION}

This study showed that sexual stage-specific seroreactivity develops after a limited number of $P$. falciparum infections in a cohort of non-immune transmigrants. The prevalence of antibodies to Pfs $48 / 45$ and Pfs 230 and functional TRA increase with the number of infections experienced. 


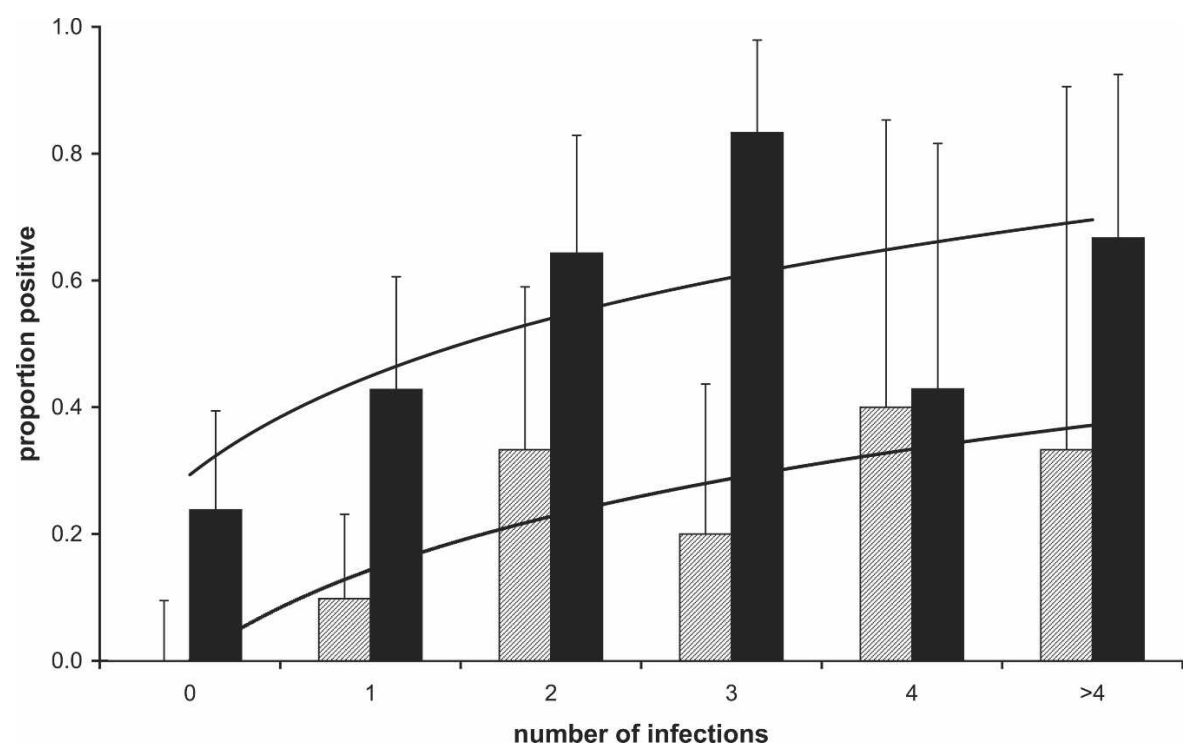

FIGURE 3. Prevalence of Pfs 230 seroreactivity as a function of the number of prior Plasmodium falciparum infections. The prevalence of Pfs230 antibodies is depicted for children (shaded bars) and adults (black bars). Error bars indicate the upper limit for the $95 \%$ confidence interval. The number of observations for children is 0 infections $(\mathrm{n}=32) ; 1(\mathrm{n}=41) ; 2(\mathrm{n}=18) ; 3(\mathrm{n}=20) ; 4(\mathrm{n}=5)$; and $>4(\mathrm{n}=3)$. For adults, 0 infections $(\mathrm{n}=42) ; 1(\mathrm{n}=35) ; 2(\mathrm{n}=28) ; 3(\mathrm{n}=12) ; 4(\mathrm{n}=7)$; and $>4(\mathrm{n}=9)$. Logistic trend lines are shown for adults (top line) and children (bottom line).

Development of sexual stage-specific immunity resembles that of immunity against asexual stages with similar patterns for acquisition of antibodies against GLURP, Pfs230, and Pfs48/45. Reactivity against all antigens develops quickly after exposure, with seroprevalence increasing with number of infections. Consistent with previous studies, immune response seems to require recent but not necessarily long-term exposure. ${ }^{11-13}$ Sexual stage-specific antibody responses seem to be part of the initial immune response, which corroborates previous studies in individuals after a primary infection with $P$. falciparum. $^{28,29}$ The finding is remarkable because exposure to sexual stage parasites is generally considered much lower than to asexual parasites. In this study, less than one-third of the individuals had microscopically detectable gametocytes on any occasion during the two-year follow-up. This apparent low exposure may be the result of poor sensitivity of microscopy in detecting low-density gametocytemia, ${ }^{30}$ which can contribute substantially to the total exposure to gametocytes. ${ }^{31}$ Sexual stage-specific antibodies may be induced by these low-density gametocytes or by gametocytes that are sequestered in capillary vessels. ${ }^{32}$ The combined possibilities may explain the frequently observed reactivity against sexual stage-specific antigens in the absence of microscopically detectable gametocytes. In addition to these antibody responses, we also frequently observed functional TRA without concurrent or prior detection of gametocytes. Although we may have missed some gametocytemic periods as a result of our screening every two weeks, we conclude that submicroscopic levels of gametocytemia play an important role in eliciting sexual stage-specific immune responses.

We found no evidence for age as a key determinant in the development of immune responses in our population of 6-40year old transmigrants. Although other studies reported an age-dependent acquisition of clinical and parasitic immunity, ${ }^{12,13}$ we did not find a similar effect for our selected markers of asexual and sexual stage-specific immunity. The reac- tivity in the ELISAs was higher in adults but could reflect background reactivity because of the presence of crossreactive antibodies reacting with common epitopes. ${ }^{15} \mathrm{We}$ did not detect a difference in the relationship between exposure to infection and the acquisition of (sexual stage-specific) immunity for different age groups.

Our most important finding was the presence of functional TRA in a substantial proportion of the individuals that increased with exposure. This has not been previously shown for $P$. falciparum, but is analogous to transmission-blocking immunity in $P$. vivax, where TRA is more prevalent and efficient after repeated infections. ${ }^{33-35}$ In this study, more than $25 \%$ of the individuals with more than four $P$. falciparum infections showed TRA, i.e., $>50 \%$ reduction in oocysts numbers. This pattern of increasing prevalence of TRA accompanies the occurrence of antibodies to Pfs 230 and Pfs48/45, as previously reported. ${ }^{8,36-39}$ The rapid development of TRA and associated antibodies is particularly promising because Pfs 230 and Pfs48/45 are considered candidates for inclusion in future transmission-blocking vaccines. ${ }^{28}$

Received September 9, 2005. Accepted for publication October 20, 2005.

Acknowledgments: We thank all the residents from SP2 for their participation in this study; the Ministry of Health in Jakarta and the Provincial Health Service of Papua in Jayapura for their support; the collaborating technicians and assistants at SP2 for a wonderful job during follow-up of participating volunteers; G. J. van Gemert for performing parasite cultures and transmission experiments; and J. P. Verhave for starting the original collaboration.

Financial support: Work in The Netherlands was supported by NWOWOTRO (WM 93-350; 2003-00702), and European Community KA2 programme 1999-2003. Work in Indonesia was supported by the Department of Defense Medical Infectious Diseases Research Program.

Disclaimer: The views and opinions are those of the authors and do not purport those of the U.S. Navy or Department of Defense.

Authors' addresses: J. Teun Bousema, Will Roeffen, Mike van der 
Kolk, Marga van der Vegte-Bolmer, Karina Teelen, and Robert W Sauerwein, Department of Medical Mirobiology 188, Radboud University Nijmegen Medical Centre, P.O. Box 9101, 6500 HB Nijmegen, The Netherlands, Telephone: 31-24-361-9515, Fax: 31-24-361-4666. Sake J. de Vlas, Department of Public Health, Erasmus University Rotterdam, P.O. Box 1738, 3000 DR Rotterdam, The Netherlands, Telephone: 31-10-408-8285, Fax: 31-10-408-9449. Michael J. Bangs, Jason D. Maguire, and J. Kevin Baird, U.S. Naval Medical Research Unit No. 2, FPO, AP 96520-8132 or JI Percetakan Negara No. 29, Jakarta 10560, Indonesia. Liliana Kurniawan, National Institute of Health Research and Development, Ministry of Health, Jakarta, Indonesia.

Reprint requests: Robert W. Sauerwein, Department of Medical Microbiology 268, Radboud University Nijmegen Medical Centre, P.O. Box 9101, 6500 HB Nijmegen, The Netherlands, Telephone: 31-24361-4306, Fax: 31-24-361-4666, E-mail: r.sauerwein@mmb.umcn.nl.

\section{REFERENCES}

1. Kaslow DC, 1993. Transmission-blocking immunity against malaria and other vector-borne diseases. Curr Opin Immunol 5: 557-565.

2. Mulder B, Lensen T, Tchuinkam T, Roeffen W, Verhave JP, Boudin C, Sauerwein R, 1999. Plasmodium falciparum: membrane feeding assays and competition ELISAs for the measurement of transmission reduction in sera from Cameroon. Exp Parasitol 92: 81-86.

3. Ponnudurai T, van Gemert GJ, Bensink T, Lensen AH, Meuwissen JH, 1987. Transmission blockade of Plasmodium falciparum: its variability with gametocyte numbers and concentration of antibody. Trans $R$ Soc Trop Med Hyg 81: 491-493.

4. Vermeulen AN, Ponnudurai T, Beckers PJ, Verhave JP, Smits MA, Meuwissen JH, 1985. Sequential expression of antigens on sexual stages of Plasmodium falciparum accessible to transmission-blocking antibodies in the mosquito. J Exp Med 162: 1460-1476.

5. Drakeley CJ, Mulder L, Tchuinkam T, Gupta S, Sauerwein R, Targett GA, 1998. Transmission-blocking effects of sera from malaria-exposed individuals on Plasmodium falciparum isolates from gametocyte carriers. Parasitology 116: 417-423.

6. Graves PM, Doubrovsky A, Sattabongkot J, Battistutta D, 1992. Human antibody responses to epitopes on the Plasmodium falciparum gametocyte antigen PFS 48/45 and their relationship to infectivity of gametocyte carriers. Am J Trop Med Hyg 46: $711-719$.

7. Healer J, McGuinness D, Hopcroft P, Haley S, Carter R, Riley E, 1997. Complement-mediated lysis of Plasmodium falciparum gametes by malaria-immune human sera is associated with antibodies to the gamete surface antigen Pfs230. Infect Immun 65: 3017-3023

8. Healer J, McGuinness D, Carter R, Riley E, 1999. Transmissionblocking immunity to Plasmodium falciparum in malariaimmune individuals is associated with antibodies to the gamete surface protein Pfs230. Parasitology 119: 425-433.

9. Carter R, Mendis K, 1992. Transmission immunity in malaria: reflections on the underlying immune mechanisms during natural infections and following artificial immunization. $\mathrm{Mem}$ Inst Oswaldo Cruz 87: 169-173.

10. Roeffen W, Mulder B, Teelen K, Bolmer M, Eling W, Targett GA, Beckers PJ, Sauerwein R, 1996. Association between antiPfs $48 / 45$ reactivity and $\mathrm{P}$. falciparum transmission-blocking activity in sera from Cameroon. Parasite Immunol 18: 103-109.

11. Andersen E, Jones TR, Purnomo, Masbar S, Wiady I, Tirtolusumo S, Bangs MJ, Charoenvit Y, Gunawan S, Hoffman SL, 1997. Assessment of age-dependent immunity to malaria in transmigrants. Am J Trop Med Hyg 56: 647-649.

12. Baird JK, Krisin A, Barcus MJ, Elyazar IR, Bangs MJ, Maguire JD, Fryauff DJ, Richie TL, Sekartuti, Kalalo W, 2003. Onset of clinical immunity to Plasmodium falciparum among Javanese migrants to Indonesian Papua. Ann Trop Med Parasitol 97: $557-564$.

13. Baird JK, Jones TR, Danudirgo EW, Annis BA, Bangs MJ, Basri H, Purnomo , Masbar S, 1991. Age-dependent acquired protection against Plasmodium falciparum in people having two years exposure to hyperendemic malaria. Am J Trop Med Hyg 45: 65-76.

14. Barcus MJ, Krisin, Elyazar IR, Marwoto H, Richie TL, Basri H, Wiady I, Fryauff DJ, Maguire JD, Bangs MJ, Barid JK, 2003. Primary infection by Plasmodium falciparum or $P$. vivax in a cohort of Javanese migrants to Indonesian Papua. Ann Trop Med Parasitol 97: 565-574.

15. Hudson Keenihan SN, Ratiwayanto S, Soebianto S, Krisin, Marwoto H, Krishnegowda G, Gowda DC, Bangs MJ, Fryauff DJ, Richie TL, Kumar S, Baird JK, 2003. Age-dependent impairment of IgG responses to glycosylphosphatidylinositol with equal exposure to Plasmodium falciparum among Javanese migrants to Papua, Indonesia. Am J Trop Med Hyg 69: 36-41.

16. Krisin, Basri H, Fryauff DJ, Barcus MJ, Bangs MJ, Ayomi E, Marwoto H, Elyazar IR, Richie TL, Baird JK, 2003. Malaria in a cohort of Javanese migrants to Indonesian Papua. Ann Trop Med Parasitol 97: 543-556.

17. Hogh B, Petersen E, Dziegiel M, David K, Hanson A, Borre M, Holm A, Vuust J, Jepsen S, 1992. Antibodies to a recombinant glutamate-rich Plasmodium falciparum protein: evidence for protection of individuals living in a holoendemic area of Liberia. Am J Trop Med Hyg 46: 307-313.

18. Dodoo D, Theisen M, Kurtzhals JA, Akanmori BD, Koram KA, Jepsen S, Nkrumah FK, Theander TG, Hviid L, 2000. Naturally acquired antibodies to the glutamate-rich protein are associated with protection against Plasmodium falciparum malaria. J Infect Dis 181: 1202-1205.

19. Soe S, Theisen M, Roussilhon C, Aye K-S, Druilhe P, 2004. Association between protection against clinical malaria and antibodies to merozoite surface antigens in an area of hyperendemicity in Myanmar: complementarity between responses to merozoite surface protein 3 and the 220-kilodalton glutamaterich protein. Infect Immun 72: 247-252.

20. Theisen M, Dodoo D, Toure-Balde A, Soe S, Corradin G, Koram KK, Kurtzhals JA, Hviid L, Theander T, Akanmori B, Ndiaye M, Druilhe P, 2001. Selection of glutamate-rich protein long synthetic peptides for vaccine development: antigenicity and relationship with clinical protection and immunogenicity. Infect Immun 69: 5223-5229.

21. Barcus MJ, Laihad F, Sururi M, Sismadi P, Marwoto H, Bangs MJ, Baird JK, 2002. Epidemic malaria in the Menoreh Hills of Central Java. Am J Trop Med Hyg 66: 287-292.

22. Jones TR, Baird JK, Bangs MJ, Annis BA, Purnomo, Basri H, Gunawan S, Harjosuwarno S, McElroy PD, Hoffman SL, 1994. Malaria vaccine study site in Irian Jaya, Indonesia: Plasmodium falciparum incidence measurements and epidemiologic considerations in sample size estimation. Am J Trop Med Hyg 50: $210-218$.

23. Ponnudurai T, Lensen AH, Leeuwenberg AD, Meuwissen JH, 1982. Cultivation of fertile Plasmodium falciparum gametocytes in semi-automated systems. 1 . Static cultures. Trans $R$ Soc Trop Med Hyg 76: 812-818.

24. Theisen M, Soe S, Oeuvray C, Thomas AW, Vuust J, Danielsen S, Jepsen S, Druilhe P, 1998. The glutamate-rich protein (GLURP) of Plasmodium falciparum is a target for antibodydependent monocyte-mediated inhibition of parasite growth in vitro. Infect Immun 66: 11-17.

25. Lensen A, van Druten J, Bolmer M, van Gemert G, Eling W, Sauerwein R, 1996. Measurement by membrane feeding of reduction in Plasmodium falciparum transmission induced by endemic sera. Trans R Soc Trop Med Hyg 90: 20-22.

26. Ponnudurai T, Lensen AH, van Gemert GJ, Bensink MP, Bolmer M, Meuwissen JH, 1989. Infectivity of cultured Plasmodium falciparum gametocytes to mosquitoes. Parasitology 98: 165173.

27. van der Kolk M, de Vlas S, Saul A, van de Vegte-Bolmer M, Eling WM, Sauerwein RW, 2004. Evaluation of the standard membrane feeding assay (SMFA) for the determination of malaria transmission reducing activity using empirical data. Parasitology 130: 13-22.

28. Ong CS, Zhang KY, Eida SJ, Graves PM, Dow C, Looker M, Rogers NC, Chiodini PL, Targett GA, 1990. The primary antibody response of malaria patients to Plasmodium falciparum sexual stage antigens which are potential transmission blocking vaccine candidates. Parasite Immunol 12: 447-456. 
29. Graves PM, Doubrovsky A, Carter R, Eida S, Beckers P, 1990. High frequency of antibody response to Plasmodium falciparum gametocyte antigens during acute malaria infections in Papua New Guinea highlanders. Am J Trop Med Hyg 42: 515520 .

30. Mulder B, van der LW, Sauerwein R, Verhave JP, 1998. Detection of Plasmodium falciparum gametocytes with the OBC test and Giemsa-stained thick blood films for malaria transmission studies in Cameroon. Trans R Soc Trop Med Hyg 92: 395-396.

31. Nassir E, Abdel-Muhsin AM, Suliaman S, Kenyon F, Kheir A, Geha H, Ferguson HM, Walliker D, Babiker HA, 2005. Impact of genetic complexity on longevity and gametocytogenesis of Plasmodium falciparum during the dry and transmission-free season of eastern Sudan. Int J Parasitol 35: 49-55.

32. Pichon G, Awono-Ambene HP, Robert V, 2000. High heterogeneity in the number of Plasmodium falciparum gametocytes in the bloodmeal of mosquitoes fed on the same host. Parasitology 121: $115-120$.

33. Mendis KN, Munesinghe YD, de Silva YN, Keragalla I, Carter R, 1987. Malaria transmission-blocking immunity induced by natural infections of Plasmodium vivax in humans. Infect Immun 55: 369-372.

34. Ramsey JM, Salinas E, Rodriguez MH, 1996. Acquired transmission-blocking immunity to Plasmodium vivax in a population of southern coastal Mexico. Am J Trop Med Hyg 54: 458-463.
35. Ranawaka MB, Munesinghe YD, de Silva DM, Carter R, Mendis KN, 1988. Boosting of transmission-blocking immunity during natural Plasmodium vivax infections in humans depends upon frequent reinfection. Infect Immun 56: 1820-1824.

36. Roeffen W, Lensen T, Mulder B, Teelen K, Sauerwein R, Eling W, Meuwissen JH, Beckers P, 1994. Transmission blocking immunity as observed in a feeder system and serological reactivity to Pfs 48/45 and Pfs230 in field sera. Mem Inst Oswaldo Cruz 89 (Suppl): 13-15.

37. Roeffen W, Geeraedts F, Eling W, Beckers P, Wizel B, Kumar N, Lensen T, Sauerwein R, 1995. Transmission blockade of Plasmodium falciparum malaria by anti-Pfs230-specific antibodies is isotype dependent. Infect Immun 63: 467-471.

38. Roeffen W, Lensen T, Mulder B, Teelen K, Sauerwein R, van Druten J, Eling W, Meuwissen JH, Beckers PJ, 1995. A comparison of transmission-blocking activity with reactivity in a Plasmodium falciparum 48/45-kD molecule-specific competition enzyme-linked immunosorbent assay. Am J Trop Med Hyg 52: 60-65.

39. Roeffen W, Teelen K, van As J, van de Vegte-Bolmer M, Eling W, Sauerwein R, 2001. Plasmodium falciparum: production and characterization of rat monoclonal antibodies specific for the sexual-stage Pfs48/45 antigen. Exp Parasitol 97: 45-49. 